\title{
Correction: S22 Bap1 expression and treatment outcomes in malignant pleural mesothelioma in a prospective uk based clinical trial
}

Kumar N, Kolluri K, Al Rifai D, et al. S22 Bap1 expression and treatment outcomes in malignant pleural mesothelioma in a prospective uk based clinical trial. Thorax 2017;72:A16-7. doi:10.1136/thoraxjnl-2017-210983.28.

The third author's name is incorrect. Instead of D Al Rifai, the correct spelling should be $D$ Alrifai.

(C) Article author(s) (or their employer(s) unless otherwise stated in the text of the article) 2018. All rights reserved. No commercial use is permitted unless otherwise expressly granted.

Thorax 2018;73:598. doi:10.1136/thoraxjnl-2017-210983.28corr1

Check for updates 